\title{
The Chaoulli challenge: getting a grip on waiting lists
}

\section{David Hadorn}

ß See related articles pages 269, 273, 275 and 277

T The vigorous reaction sparked by the Supreme Court's decision on June 9, 2005, in the case of Chaoulli v. Quebec (Attorney General) - to permit private health insurance in Quebec $^{1}$ - gives reason for hope that the court may have resuscitated Canada's longmoribund discussion on the proper limits of publicly funded health care. The Chaoulli challenge, as it might be called, is to face up to the reality and inevitability of such limits and to develop fair and evidence-based procedures for deciding what they should be. This difficult but unavoidable task involves drawing lines between services that must be provided to Canadians as a matter of justice and those that can be safely relegated to the private market.

The focus of the court's challenge was, of course, on waiting lists, and it is in this arena that supply and demand are most chronically and conspicuously mismatched. But how serious is the problem, really? Are waiting lists and waiting times in Canada unreasonably long? To answer these questions with any certitude, we must know something about the people who are waiting, and here, we are almost entirely at a loss. The too few studies that have measured health-related quality of life among patients on waiting lists (in Canada and elsewhere) have in fact shown that while some patients are seriously affected and should no doubt have shorter waits, others have quite marginal degrees of suffering or impairment, compatible with much longer waits. ${ }^{2-6}$ (Indeed, anecdotal evidence from Canada and New Zealand suggests that surgeons sometimes place minimally affected patients on waiting lists in anticipation that their symptoms will worsen while waiting.) Little information is available concerning the extent to which waiting times are correctly matched with varying degrees of clinical urgency.

Given this rather primitive state of knowledge, the only justified reply to the question of whether waiting times are too long would seem to be "we don't know" or perhaps "waits are no doubt unreasonably long for some patients and not for others, but we have no valid means for distinguishing one from the other." Neither reply is particularly satisfying, but as Supreme Court Justices Binnie and LeBel pointed out, ${ }^{7}$ the lack of relevant information and applicable standards for demarcating unreasonably long waits from reasonably long ones forced the court majority to indulge in a kind of "know it when we see it" approach.

If we wish to truly understand the waiting list situation and to develop non-arbitrary standards for reasonable waiting times, we must have access to much better information. A necessary beginning in this regard would be for the provincial health plans to require providers to collect stan- dardized information on the urgency status of all patients placed on public waiting lists. Assessments of urgency would use measures designed for this purpose, such as the criteria developed by the Western Canada Waiting List Project $(W C W L)^{8}$ and the New Zealand Priority Criteria Project (NZPC), ${ }^{9}$ which incorporate symptoms, physical findings and other factors required to develop informed judgments about reasonable waiting times.

A good example of how standardized assessment criteria can inform these judgments is found in an exercise undertaken by the WCWL, in which doctors, surgical patients and members of the general public were asked to estimate "maximum acceptable waiting times" for patients with different degrees of clinical urgency. ${ }^{10}$ Patients used themselves as referents, whereas doctors and participants from the general public were provided with detailed patient descriptions based on WCWL criteria (see Appendix 1 for an example). Several scenarios reflecting various degrees of severity were developed for this exercise. The point-count scores associated with these scenarios can then easily be matched with actual patients on waiting lists. In this way, judgments of the reasonableness of waiting times can rest on a more secure foundation.

Of interest, the estimated maximum acceptable waiting times derived from public input in the WCWL study were longer than those deemed reasonable by physicians or patients. ${ }^{10}$ For example, members of the general public considered a wait of almost 3 years (147 weeks) to be reasonable for people with mild hip or knee pain; even patients with severe symptoms were considered able to wait over 6 months (28 weeks). These values contrasted sharply with those suggested by physicians (26 and 4 weeks, respectively) and patients (12 and 4 weeks, respectively). Because the statistical method used to estimate waiting times from public input differed from that used with input from doctors and patients, it is not possible to attribute the marked differences in estimates to any specific factor. Nevertheless, the results are intriguing and deserve further study. After all, would it be so unreasonable to ask people to endure 2 or 3 years of mild pain before a publicly funded hip replacement is made available?

Standardized assessment criteria can also be used to specify numeric thresholds below which patients' conditions are deemed insufficiently urgent to warrant receiving publicly funded surgery. Surgical waiting lists in New Zealand have been managed like this for several years, although there are no strict rules prohibiting patients "below the threshold" from receiving surgery in the public sector. In practice, however, most such patients either go without surgery or avail themselves of private surgery. Private insurance is 
available to pay for services deemed insufficiently urgent to meet applicable thresholds for publicly funded care or for patients who are "above the line" but do not wish to wait.

The use of such objective criteria to draw lines in this manner is compatible with considerations of distributive justice, as articulated by the well-respected US President's Commission for the Study of Ethical Problems in Medicine and Biomedical and Behavioral Research. ${ }^{11}$ The commission concluded that the State has "an ethical obligation to provide an adequate level of care" to its citizens and residents. Although the notion of "adequate care" cannot be specified in the abstract, the concept is operationalized by such terms as, in the present context, "reasonable waiting times" and "appropriate public thresholds" for surgery. Provided the adequacy of waiting times and thresholds is guarded by a public, accountable process, there is no ethical reason why people should not be free to buy insurance that covers "more-than-adequate" care. ${ }^{12}$ (In New Zealand, responsibility for guarding adequacy rests with the National Advisory Committee on Health and Disability, through the committee's charge to "provide an independent assessment to the Minister of Health on the quality and mix of services that should, in the Committee's opinion, be publicly funded." ${ }^{13}$ ) Without such a means for distinguishing adequate from more-than-adequate care, however, or for defending the adequacy of any specified thresholds, the expansion of private health insurance in Canada would be unlikely to meet the dictates of distributive justice.

Before leaving this topic, it is worth acknowledging the concerns that exist about physicians' propensity to "game the system" (i.e., to exaggerate patients' symptoms out of compassion and a desire to see the patient treated as quickly as possible). One way to alleviate this concern is to adopt a policy whereby neutral third-party clinicians perform the patient scoring. This approach has been successfully used in New Zealand, and experience has shown that patients are less prone to exaggerating their own symptoms than are doctors on their behalf. Moreover, the perception of fairness fostered by the use of standardized criteria, which may be the greatest advantage of this approach, can in itself be expected to facilitate honesty.

Once it is accepted that not all demand can be supplied through tax dollars, the task becomes one of managing demand in accordance with principles of distributive justice, as just outlined. However, managing demand is not the same as reducing (or even limiting) demand, and additional measures will doubtless be required if thresholds for the public provision of waiting-list services are to meet the test of adequacy.

One promising measure for reducing demand might be to launch a major effort to foster more systematic and innovative use of nonsurgical measures to ameliorate the suffering and impairment that often drives patients to seek surgical treatment. Such an effort could include more vigorous and sophisticated treatment of chronic pain (much needed in its own right) and more aggressive use of supportive devices such as large-type computer screens for pa- tients with visual impairment or custom-designed canes for patients with hip or knee pain. Such measures are sometimes all that is needed to satisfy many patients.

What can be done on the "supply" side? Here the goal is primarily to search for (or develop) system efficiencies, and several possibilities exist.

Among the most commonly proposed measures for enhancing efficiency are the auditing and pooling of waiting lists. ${ }^{14}$ Neither of these practices occurs to any significant extent in Canada; both would probably produce significant, if perhaps modest, efficiencies. More substantial savings might be found by continuing to increase the use of outpatient facilities rather than hospitals and to use "clean rooms" rather than fully fledged operating theatres for relatively simple procedures (e.g., cataract surgery performed with the use of local anesthesia). Given that up to half of the cost of surgical procedures can be attributed to operating theatres, substantial savings may be realized through this approach, assuming that quality of care can be maintained.

Another method of enhancing efficiency might involve increasing surgeons' productivity, perhaps through the use of specially trained assistants to help perform (or to perform themselves) many of the simple tasks and procedures traditionally done by doctors. For example, in recent years, New Zealand ophthalmologists have been training office nurses to perform such procedures as visual acuity assessment, measurement of ocular pressure, tear-duct irrigation, glaucoma management and screening for diabetic retinopathy. Provided the surgeon remains in charge and supervises these activities to an appropriate extent, it is unlikely that quality of care would suffer. Ideally, the existence of such assistants would improve the surgeon's productivity while freeing him or her up for more challenging pursuits, especially the more complicated procedures for which patients are waiting. Naturally, there may be some concern about assistants "taking over" doctors' legitimate purview, but most physicians will probably realize that some such change in the provider landscape is required owing to relentless pressures on costs and surgeons' time. In the United States, the use of clinical assistants is already quite common, and this experience should be closely examined before a similar approach is implemented in Canada.

Through a combination of supply- and demand-side measures, it should be possible to transform waiting lists into an accepted social phenomenon of relatively modest concern. There will always be a market for care beyond the "adequate" level, however, and private health insurance, if properly restricted, could play a legitimate role in helping Canada balance the worthy goals of social solidarity and freedom to pursue one's own good. The Chaoulli challenge, if embraced, could greatly facilitate the quest for this elusive balance.

David Hadorn was Manager of the New Zealand Priority Criteria Project and Research Director of the Western Canada Waiting List Project.

Competing interests: None declared. 


\section{References}

1. Chaoulliv. Quebec (Attorney General). 2005 SCC 35.

2. Sempalis J, Boukas S, Liberman M, Reid T, Dupuis G. Impact of waiting time on the quality of life of patients waiting for coronary artery bypass graft surgery. CMA7 2001;165(4):429-33.

3. Hadorn DC, Holmes AC. The New Zealand Priority Criteria Project. II. Coronary artery bypass graft surgery. BM7 1997;314:135-8.

4. Williams JI, Llewellyn TH, Arshinoff R, Young N, Naylor CD. The burden of waiting for hip and knee replacements in Ontario. Ontario Hip and Knee Replacement Project Team. 7 Eval Clin Pract 1997;3:59-68.

5. Derrett S, Paul C, Morris JM. Waiting for elective surgery: effects on healthrelated quality of life. Int 7 Qual Health Care 1999;11:47-57.

6. Riley AF, Grupcheva CN, Malleck TY, Craig JP, McGee CN. The waiting game: natural history of a cataract waiting list in New Zealand. Clin Experiment Ophthalmol 2001;29:376-80.

7. Chaoulli v. Quebec (Attorney General) 2005 SCC 35 at para 163, Binnie and LeBel JJ, dissenting.

8. Noseworthy TW, McGurran JJ, Hadorn DC; Steering Committee of the Western Canada Waiting List Project. Waiting for scheduled services in Canada: development of priority-setting scoring systems. F Eval Clin Pract 2003;9:23-31.

9. Hadorn DC, Holmes AC. The New Zealand Priority Criteria Project. I. Overview. BM7 1997;314:131-4.

10. Western Canada Waiting List Project (WCWL). The Waiting Time Project. In: Moving forward. Calgary: WCWL; 2005. ch 3. Available: www.wcwl.org /media/pdf/news/moving_forward/report.pdf (accessed 2005 Jul 6).

11. President's Commission on the Study of Ethical Problems in Medicine and Biomedical and Behavioural Research. Securing access to bealth care: the ethical implications of differences in the availability of health services. Washington: US Government Printing Office; 1983.

12. Hadorn DC. Creating a just and affordable system of national health insurance through democratically determined limits on "adequate" and life-prolonging care [dissertation]. Boulder (CO): University of Colorado; 1988 Available: www.davidhadorn.com/thesis.html (accessed $2005 \mathrm{Jul} 6$ ).

13. National Health Committee. Role of the National Advisory Committee on Health and Disability. Wellington (NZ): The Committee. Available: www.nhc.govt.nz /about/rolenhc.html (accessed 2005 Jul 6).
14. Lewis S, Barer M, Sanmartin C, Sheps S, Short SED, McDonald PW. Ending waiting-list mismanagement: principles and practice [editorial]. CMAJ 2000;162(9):1297-300.

Correspondence to: Dr. David Hadorn, 282 Mt. Fyffe Rd., Kaikoura NZ; dhadorn123@fastmail.fm

Appendix 1: Example of patient description based on WCWL criteria provided to participants to estimate "maximum acceptable waiting times" for patients with different degrees of clinical urgency ${ }^{10}$

A patient with hip or knee arthritis has:

- Severe pain on motion (e.g., while walking or bending)

- Moderate pain at rest (e.g., while sitting or lying down)

- Ability to walk less than 1 block without significant pain

- Severe limitations (e.g., unable to perform most activities, such as putting on shoes, managing stairs, standing from seated position, sexual activities, bathing, cooking, recreation or hobbies)

- Severe abnormal findings on physical examination related to affected joint

- Ability to fulfil their role and independence in society that is threatened but not immediately (e.g., ability to work, care for dependents or live independently)

Note: $\mathrm{WCWL}=$ Western Canada Waiting List Project.

\section{The private sector in the English NHS: from pariah to saviour in under a decade}

\section{Richard Smith}

ß See related articles pages 269, 271, 275 and 277

I must make it clear that I am writing about the NHS in England only. Health is a "devolved" issue, and the health services in the 4 countries of the United Kingdom are rapidly diverging.

$\mathrm{U}$ ntil recently the private sector played an unimportant part in England's health services. Well over $95 \%$ of interactions between a patient and doctor took place in the public sector. Private general practitioners existed only in isolated pockets. Emergency hospital care was all in the public sector, and the private sector was concerned mainly with elective surgery. Patients "went private" simply to jump queues. Now - suddenly — the government is looking to the private sector to save the National Health Service (NHS), causing many to worry that the NHS is to follow airlines, telecommunications and railways into the private sector. Why the change?

Margaret Thatcher, the queen of privatization, didn't dare privatize the NHS. Instead, she said that she wanted to make it so good that nobody would need the private sector. Despite being a risk taker, she went against her ideological instincts because she knew that the NHS mattered too much to the English. Our belief in it is almost religious - despite the fact that it embodies socialist values that were dominant in 1948, when the NHS was founded, but have disappeared from much of English life.

The relationship between the public and private sectors in health care has been complicated since the start of the NHS. General practitioners were from the beginning "independent contractors" rather than employees. But nobody has thought of them as being in the private sector, and they enjoy a generous NHS pension.

Chunks have been falling off the NHS and into the private sector almost since the beginning. Glasses were the first to go, and dentistry soon followed. Some in England (including me) are privileged to have an "NHS dentist," although we still have to pay something, but most dental pa- 